Topic 4: Improving livelihoods and protecting biodiversity

\title{
Protecting forests and biodiversity: Are investments in eco-friendly production activities the best way to protect endangered ecosystems and enhance rural livelihoods?
}

Paul J. Ferraro

R. David Simpson

Paper presented at

The International Conference on

Rural Livelihoods, Forests and Biodiversity 19-23 May 2003, Bonn, Germany 
Protecting forests and biodiversity: Are investments in eco-friendly production activities the best way to protect endangered ecosystems and enhance rural livelihoods?

Paul J. Ferraro

R. David Simpson 


\section{INTRODUCTION}

Governments and citizens throughout the world are concerned with saving biodiversity. However, many biologically diverse ecosystems, including the majority of tropical rainforests, are located in low-income nations that receive few of the global benefits from their ecosystems. With limited resources and myriad pressing social needs, these nations are not in a position to provide global ecosystem services gratis.

To help low-income nations conserve their endangered ecosystems, international conservation and development donors have made substantial investments over the last two decades. These donors include bilateral aid agencies (USAID, GTZ), multilateral institutions (World Bank, GEF), and private organizations (MacArthur Foundation, Moore Foundation). While aggregate figures do not exist, we estimate that international sources of conservation funds have invested some $\$ 10$ billion to induce conservation in low-income nations. ${ }^{i}$

To allocate these funds, international donors, host-country governments and conservation practitioners have experimented with various mechanisms. The most popular vehicle for conservation investment over the last two decades has been the Integrated Conservation and Development Project (ICDP). ${ }^{\text {ii }}$ These initiatives typically provide assistance to ventures that yield commercial outputs and ecosystem protection as joint products. Examples of such eco-friendly ventures include ecotourism, biodiversity prospecting, non-timber forest product extraction, and selective logging. These ventures typically employ relatively undisturbed ecosystems as inputs. The ecosystems are combined with purchased inputs such as capital and labor to produce a valuable output, such as tourist excursions, novel chemical compounds, fruits, or timber.

All of the major international development and conservation agencies have made investments to support eco-friendly ventures near endangered ecosystems. ${ }^{\text {iii }}$ Funds are often directed towards increasing the eco-output price or facilitating the acquisition of complementary inputs, such as tourism infrastructure, product marketing, and processing facilities. The assumption underlying such interventions is simple: local agents, faced with cheaper inputs or higher output prices for an ecofriendly activity, will demand a greater area of intact ecosystem, thereby indirectly protecting ecosystems and their constituent services.

The introduction of new technologies and employment opportunities in rural environments can be a challenge, however (World Bank 1988). Not surprisingly, many reviews of conservation interventions report that investments in eco-friendly activities have had limited success in achieving their conservation and development objectives (Wells and Brandon 1992; Ferraro et al. 1997; World Bank 1997; Oates 1999; Ferraro, 2001; Terborgh et al., 2002). Such investments have been assailed for a number of reasons: erroneous assumptions about the desires of local people to protect nature, ambiguous effects on conservation incentives, complex implementation needs, and lack of conformity with the temporal and spatial dimensions of ecosystem conservation objectives (Ferraro et al. 1997; Brandon, 1998; Southgate 1998; Chomitz and Kumari 1998; Simpson 1999; Ferraro 2001; Terborgh and van Schaik, 2002). 
An alternative approach to encouraging the conservation of endangered natural ecosystems is to pay for conservation performance directly. In this approach, domestic and international actors make payments to individuals or groups that protect ecosystems and thereby supply public services of ecological value (Barbier and Rauscher 1995; Barrett 1995; Simpson and Sedjo 1996; Ferraro 2001; Ferraro and Simpson, 2002; Ferraro and Kiss, 20023). We believe that there is considerable wisdom in the colloquial economic aphorism that "You get what you pay for." The corollary advice we would offer conservation donors and practitioners is "You should pay for what you want to get." That is, if donors and practitioners want to achieve conservation, they should pay for conservation, not for activities they believe are related to conservation. We develop this point more thoroughly in the next section of the paper.

We also emphasize a corollary that speaks directly to the nexus between conservation and livelihoods. Much of the impetus for indirect funding approaches has come from the desire simultaneously to achieve conservation and development goals. We demonstrate in the next section that, for a given conservation budget, there is generally no tradeoff between development and conservation goals when choosing a direct approach instead of an indirect approach. Direct payments should prove more effective in achieving both goals.

In the next section, we describe the economics of direct and indirect approaches to protecting ecosystems and biodiversity. In sections III-V, we address common criticisms of direct payment approaches and attempt to answer the question, "If direct approaches are more desirable, why have indirect approaches been more commonly employed in recent years?" In section VI, we offer a brief review of how direct payments are working in practice around the world.

\section{THE ECONOMICS OF CONSERVATION}

A private landowner will devote her holdings to whatever activity provides her with the greatest benefits (in the next section, we address the issue of property rights-i. e., when can we speak meaningfully of there being a "private landowner"?-in more detail). Such benefits might be purely financial, purely esthetic, purely ethical, or, as is true to some degree for almost all of us, some combination of pecuniary and intangible rewards. The important point is that landowners must be compensated for their "opportunity cost"-whatever other benefits they forego - if they are to conserve land.

A direct approach to conservation is straightforward; it is a quid pro quo. If the landowner takes actions that demonstrably result in the conservation of the resources under her control, she will receive something she values. Compensation need not be in the form of cash (although there may be good reasons for offering it in the form of cash). The important aspect of compensation we are trying to emphasize is that it be paid in exchange for specific performance.

Under an indirect approach, such as an ICDP, a conservation donor offers the landowner something that may make her more likely to pursue eco-friendly activities. Her investment in a hotel to house eco-tourists might be subsidized. She could be given equipment with which to evaluate bioprospecting samples. She might be 
offered free seedlings for reforestation, or access to marketing networks for distributing nontimber forest products.

The argument for the superiority of the direct approach can be captured in two simple rhetorical questions. First, why is any subsidy required to induce a private landowner to undertake an eco-friendly commercial activity? Second, if a subsidy is required to make an eco-friendly activity viable, would it not make more sense to use the amount of the subsidy to pay for conservation directly?

Before undertaking an indirect approach to conservation, all practitioners should answer the first question. Conservation advocates often accuse profit-seeking businesses of despoiling tropical forests. Many of these same advocates also claim that eco-friendly enterprises can be financially viable and self-sustaining if they are provided with initial funding. If, however, businesses are so eager to turn a profit, why have they failed to recognize the profit-making opportunities that conservation advocates claim lie waiting to be exploited?

We do not dispute that there are some "win-win" opportunities in which ecoentrepreneurs both "do good and do well" by establishing profitable, ecologically benign, ventures. Ranchers in the nations of southern Africa, for example, have realized greater earnings from allowing indigenous wildlife to graze their land and attract tourists than from raising cattle (Bond, 1993; Heal, 2000; Muir-Leresche and Nelson, 2000). Private landowners in Costa Rica prefer to maintain their holdings as natural reserves than to deforest them (Langholtz, et al., 2000). There are doubtless other such examples.

We do, however, dispute the notion that private decision-makers are missing large numbers of such "win-win" opportunities. It strains credulity to suppose that a conservation advocate can better identify profitable opportunities than can investors who make their living doing so. Conservation advocates who claim that eco-friendly enterprises are commercially viable with just a modicum of external funding face at least four challenges to their credibility. First, they are not experts in investment. Second, they have a powerful ulterior motive that interferes with their ability to identify the profit-maximizing use of an ecosystem: they want to conserve biodiversity, rather than to make money. Third, given the magnitude of the problem they face, they may be unusually susceptible to wishful thinking (see section V). Finally, as we will discuss in more detail in section $\mathrm{V}$, indirect approaches to conservation investment present more opportunities for financial conflicts of interest than do direct approaches.

Given how much experimentation there has been with indirect approaches to conservation investment, surprisingly little empirical evidence of their success or failure is available. However, the results of the one reasonably careful empirical study are damning. Nicholas Salafsky and his coauthors investigated financial data from 37 eco-enterprises subsidized by the USAID-funded Biodiversity Support Program. Despite applying extremely generous criteria, they found that that the vast majority failed to cover their costs (Salafsky et al., 1999). ${ }^{\text {iv }}$

If subsidies are required to launch eco-friendly enterprises that would otherwise not prove profitable, one must answer our second question. Would it not 
make more sense to take the money being applied to subsidies and use it instead to pay for conservation performance directly?

With a simple analogy and a diagrammatic argument, we can demonstrate that it would.

The analogy is as follows. Imagine that you need to drive from point $A$ to point $B$ and there are two possible routes: a circuitous one and a direct one. Taking either route will bring you to point $\mathrm{B}$, but taking the circuitous route will require more fuel. If you only have a single tank of fuel, taking the direct route will improve the likelihood that you will arrive at your destination. An indirect approach to conservation is, by definition, a circuitous route to a conservation objective and thus will require greater resources to achieve the objective. To ensure that scarce conservation funds go as far as possible towards achieving conservation objectives, practitioners and donors should consider taking the most direct route available: paying for conservation performance.

We present our argument graphically in Figure 1. The vertical axis measures the earnings received from using an area of forest. The landowner can protect all or part of the forest and pursue an eco-friendly activity, such as tourism or bioprospecting, or she can clear all or part of the forest and pursue an alternative activity, such as logging followed by agriculture. The horizontal axis measures the total amount of land that can be devoted to one activity or the other. If we denote the length of the horizontal axis as $H$, then any point $h$ on that axis represents an outcome in which an area of habitat of size $h$ is preserved for use in the eco-friendly enterprise and the remaining area $H-h$ is devoted to the ecologically destructive alternative.

The curve labeled $R$ that rises from left to right denotes the earnings received from the eco-friendly activity. Its height at any point $h$ represents earnings derived when an area $h$ is devoted to the eco-friendly activity. The curve labeled $C$ that rises from right to left denotes earnings received by converting natural habitat to alternative use. Its height at any point $h$ represents earnings derived when an area $H-h$ is devoted to the eco-friendly activity. Note that the curves labeled $R$ and $C$ are concave: they increase at a decreasing rate. This reflects the fundamental economic principle of diminishing returns. The more resources are devoted to an activity, the more benefits are derived from it, but these benefits grow at a declining rate.

The curve we have labeled $R+C$ represents total earnings from both the eco-friendly activity and the alternative. This sum is greatest at the point in Figure 1 at which an area $h^{*}$ is retained in natural habitat for use in an ecofriendly activity, and the remainder of the area, $H-h^{*}$, is converted to alternative use. Note, however, that the ecofriendly activity loses money when it is run at a small scale. In economic parlance, certain "fixed costs" must be paid if the eco-friendly activity is to take place at all. Unless a subsidy is granted to offset these fixed costs, a private landowner would prefer to convert the entire area, $H$, to the alternative activity: the point at which the curve labeled $C$ intersects the left vertical axis is higher than the peak of the summation curve $R+C$.

Suppose next that an outside donor offsets the fixed costs of undertaking the ecofriendly activity by providing a subsidy $S$. This shifts the total earnings resulting from retaining an area $h^{*}$ in natural habitat from $R+C$ to $R+C+S$. As a result of 
paying $S$, the total area conserved jumps from 0 to $h^{*}$. This may seem a clever solution to a vexing problem. A large, discrete increase is realized in the area conserved.

Actually, it is not a very well thought out conservation policy. By paying an amount $S$, an area of habitat of size $h^{*}$ is preserved. But suppose that the conservation donor had $S$ to offer in exchange for the landowner's commitment not to clear a specified area of land. Let $C\left(H-h^{* *}\right)$ denote the earnings that the landowner would realize by retaining an area of natural habitat of size $h^{* *}>h^{*}$ and converting the remaining $H$ $h^{* *}$ hectares to an alternative activity. You can see that $C\left(H-h^{* *}\right)+S=C(H)$. So, if instead of subsidizing the ecofriendly activity by investing $S$ to offset its fixed costs, a conservation donor could actually save more habitat by simply paying the landowner her opportunity cost of foregoing conversion of $h^{* *}>h^{*}$ hectares of habitat.

We have given the example above because we feel that it best conveys a basic principle: if it does not make economic sense in profit-and-loss terms to subsidize eco-friendly ventures, such subsidies do not constitute a wise conservation strategy. We think that this is most easily seen in an example of the type we have given, in which the conservation donor subsidizes an eco-friendly venture's fixed costs. The argument generalizes, however. In the long run even large investment expenses are not literally "fixed". Entrepreneurs must decide at what point along a continuum of possible scales it wishes to operate. Moreover, investments in fixed assests depreciate and must eventually be replaced. Finally, there are various ways in which to subsidize an eco-friendly enterprise. A conservation donor might enable an ecofriendly enterprise to reduce its variable costs by, for example, providing concessionary financing or assisting in employee training. Arguments analogous to that we have just presented establish that these are also very cost-ineffective as conservation strategies (Ferraro and Simpson, 2002).

In fact, they can be spectacularly ineffective, increasing the costs of conserving a given area of ecosystem many times over in some instances. For example, an analysis of a conservation intervention in southeastern Madagascar (Conrad and Ferraro, 2002) indicates that, were the nearly $\$ 4$ million of available conservation funds invested in annual payments conditional on the protection of forest, about $80 \%$ of the original forest could have been protected into perpetuity, whereas only $12 \%$ could have been protected through support of indirect incentives (see also Ferraro and Simpson, 2002).

We might also point out that we have been presuming that subsidizing eco-friendly economic activities is, in fact, a conservation strategy. A number of authors have documented instances in which ecotourism, sustainable harvesting, and related initiatives have done more harm than good (Peters, 1994; Roe, et al., 1997; Brandon, 1998; Honey, 1999). What we are saying, then, is that in a "best-case scenario" the indirect approach to conservation may prove a spectacularly ineffective way to achieve conservation ends. In a worst-case scenario, indirect subsidies can be spectacularly expensive and exacerbate biodiversity loss.

Let us conclude this section by noting that many donors invest in ICDPs because, as the abbreviation suggests, they are interested in conservation and development. This is entirely appropriate. It would be inexcusable to ask some of the world's poorest nations to bear the burden of conservation without, at the very least, compensating 
them fully for the benefits they forego as a result. So, do investments in integrated conservation and development programs make up in benefits to the poor what they lack in conservation cost-effectiveness?

The answer is another resounding "No!" Refer again to Figure 1. Recall that a habitat area of size $h^{*}$ could be retained by providing the eco-friendly enterprise with a subsidy in the amount $S$. Alternatively, for the same amount of money, a habitat area of size $h^{* *}>h^{*}$ could be retained. Note that whether the landowner simply converts all her land to alternative use, the eco-friendly enterprise is subsidized at the rate $S$ and the landowner retains an area $h^{*}$ of natural habitat, or if the landowner is paid $S$ directly in exchange for an agreement to retain an area $h^{* *}$ in natural habitat, the landowner's income is the same. She receives an amount equivalent to $C(H)$, the income she would realize if she converted the habitat at her disposal entirely to alternative use. In economic parlance, she is compensated for her entire opportunity cost.

These observations suggest another alternative. If a conservation donor is especially concerned with helping the landowner to improve her standard of living, the donor could overpay for conservation. In the context of Figure 1, the donor could pay the landowner the amount of the subsidy, $S$, in exchange for the landowner's commitment to retain at least $h^{*}$ hectares of natural habitat $\left(h^{*}<h^{* *}\right)$. Now theThe landowners's income would increase to $C\left(H-h^{*}\right)+S>C(H)$.

In short, the donor can meet both conservation and development objectives more efficiently with direct payments. The intuition underlying this claim is simple. The conservation donor wants to achieve a conservation objective and the landowner wants to achieve a higher income. The indirect approach, however, uses up much of the scarce conservation funds in achieving two outcomes that neither the conservation donor nor the landowner cares about: increasing the use of inputs in eco-friendly activities and generating additional output from eco-friendly activities. In contrast, the direct approach focuses investment on the outcomes about which the two parties care most.

\section{OWNERSHIP}

The discussion may seem surreal to anyone with a passing familiarity with the institutions of developing countries. Land ownership is well defined in most wealthy countries, but "ownership" of land in low-income nations is often ill-defined and complicated.

Having said that, however, a number of facts should be considered. First, while formal ownership rights are often not recorded in developing countries, there generally are de facto owners of property. In fact, it is surprising, given how often the claim is encountered that property rights are not well defined in the imperiled habitats of the developing world, how much evidence there is to the contrary. Groups in Latin America, Africa, Asia, and elsewhere assert rights to ownership over a variety of lands and resources (ILO, 1995; Borrini-Feyerabend, 1997; de Soto, 2000). Villagers in Madagascar and Nepal were able to identify their holdings in aerial photographs (Borrini-Feyerabend, 1997; Poole, 1995). Discussions of how to overcome social and institutional barriers to conservation mention steps such as establishing "a system to 
monitor land ownership and land values in sensitive areas," and recommend starting a conservation project by preparing land use maps to provide "a snapshot of the local situation, including property boundaries" (Borrini-Feyerabend, 1997, emphasis added). It seems, then, that at least some conservation activists implicitly assume that ownership can be defined.

A second fact is that the need to identify owners is not obviated by indirect approaches. An effective conservation approach is one in which people who have control over the resources that outside donors and practitioners want to see preserved are provided incentives sufficient to preserve such resources. This means that some agent is going to be afforded incentives sufficient to induce him to both not despoil resources himself and prevent others from doing so. This agent will be the de facto "owner."

In short, property rights are a precondition to any effective conservation strategy, and values sufficient to justify their establishment and enforcement are a precondition for property rights. Conservation donors must pay enough to make conservation worthwhile. The first element of success is offering up enough money to make property rights worth establishing.

\section{MAKING DIRECT PAYMENTS WORK}

Our discussion of the simple economics of payment programs may also have seemed unrealistic in its references to simply "paying for" conservation. The previous section addressed the question "Pay whom?" Let us now discuss for a moment the question "Pay how?"

We kept our earlier discussion simple in order to present one idea at a time, but we should now make two things clear. The first is that we did not mean to imply that payments must be made in cash. There may be good reasons for doing so, but there may also be good reasons for making payments in kind. Second, we also did not mean to imply that a conservation donor would simply pay once for the preservation of a certain area of habitat and assume that, as a result of such a payment, the area would be protected in perpetuity.

Let us elaborate on each point in turn. The first thing that might be said about cash payments is that "man does not live by bread alone." Economists often assume an abstract homo economicus whose rationality extends so far as indifference to the form in which he receives compensation. Yet real people do hold some transactions out of the economic realm (consider, for example, the social taboos against trading sex or votes for money). Moreover, psychological studies suggest that people can be so offended by offers of compensation for things for which they regard "virtue as its own reward" as to devalue them subsequently (Thompson, 2002).

These considerations are important, but we might be skeptical of claims that payments for the preservation of imperiled ecosystems will be ineffective because they will engender resentment or ill will among their recipients. After all, what is the threat to imperiled ecosystems? If people were willing to forego monetary or otherwise material benefits from the natural systems they inhabit, there would not be a problem! 
An advantage of cash payments is that they provide the advantage of flexibility when recipients can use the proceeds to purchase a wide variety of goods. One of the endemic problems of developing countries is that their markets are often not large, varied, and efficient. One concern in particular is that credit markets are inefficient, and hence that people in developing countries find it difficult to make investments larger than can be financed with cash-on-hand (see, e. g., Lucas, 1988).

This last observation might be cited as an argument for subsidizing eco-friendly activities. If foreign donors can afford investments domestic entrepreneurs cannot, might subsidizing eco-friendly activities constitute an efficiency-enhancing intervention in imperfect credit markets? We would raise two concerns here. First, supposing that ICDPs represent the most important form of investment for a developing country seems to us to raise again the question of whether conservation donors and practitioners feel themselves to be more expert in making investment choices than are professionals in the field. Moreover, it flies in the face of evidence that education, health care, and other such essentials may prove to be far better investments. Is it wiser for a developing country, or a community therein, to devote precious investment resources to such specialized — and consequently, risky-areas as ecotourism or bioprospecting? Would it not make more sense to train young people to be better prepared to seize a wider range of opportunities?

Our second concern is that, from a conservation angle, the question is not the form in which payments are made so much as that they be made in exchange for an explicit assurance of conservation performance. It may well be that certain communities will demand compensation in the form of assistance in launching eco-friendly ventures. If this is the case, conservation donors ought to have no greater objections than they would if the local people had asked for an equivalent cash outlay, a dental clinic, or another form of compensation. The critical issue is that conservation donors should make it clear "You have asked for this assistance in exchange for your promise to maintain a specified area of habitat in a specified biological condition. Our assistance to you is conditional on your fulfilling that promise."

This last notion leads us into the second major theme of this section. One would have to have a very rosy view of human nature to offer a one-time payment in exchange for a promise of perpetual performance! ${ }^{\mathrm{V}}$ For this reason, an ongoing series of payments will be required in order to maintain ongoing incentives for conservation. Donors thus correctly perceive direct payments as problematic. In contrast, indirect approaches seem to hold out the promise of short-term investments leading to longterm conservation benefits. As we have argued throughout this paper, however, there is little if any evidence that such "self-financing" conservation activities exist. Indirect approaches are also likely to require a sustained flow of funds over time to maintain conservation outcomes over the long-term. As a recent World Bank analysis of ICDPs (Wells et al. 1998) concluded, conservation initiatives "based on simplistic ideas of making limited short-term investments in local development and then hoping this will somehow translate into sustainable resource use and less pressure on parks need to be abandoned." 


\section{THE POLITICAL ECONOMY OF CONSERVATION}

The economic arguments for "paying for what you want to get" as opposed to subsidizing eco-friendly economic activities in the hopes that they will have the desired conservation incentives are powerful. Yet most commentators agree that the indirect approach has been most common over the past twenty years. Why? A number of factors must be considered.

One is historical. For much of history setting aside natural areas was a prerogative of royalty, who maintained hunting and leisure parks for their own use and severely punished commoners who intruded on them (Davenport and Rao, 2002). When Europeans colonized Africa, Asia, and the Americas, they often followed the same heavy-handed practices in establishing parks and protected areas with little or no regard for native peoples. The practice of paying for conservation directly rather than taking more active steps to involve local peoples may bear an unfortunate superficial resemblance to the colonialism of an earlier era.

The resemblance is only superficial, however. While overheated debates engender charges of economic imperialism and bullying, what is wrong with paying people for the preservation of the biological diversity whose fate they control? It may be, as we have suggested above, more honest and fair than pretending that they stand to benefit more than they will from economically dubious ICDPs.

Perhaps more importantly, conservation donors and practitioners must be realistic. Biodiversity is now imperiled in the developing world because the material benefits local people will realize from its destruction exceed those they stand to gain from their preservation. Tropical forests are, in John Terborgh's words, "worth more dead than alive" (Terborgh, 1999). Some might long for a return to the days in which local people lived out their days in noble, but ecologically benign, poverty. Those days are gone, and cannot be wished back.

Wishful thinking is, in fact, a large part of the problem. The problem is so big, and the resources so limited, some think we have to take bold and unconventional steps and pray for a miracle. Furthermore, biodiversity conservation and economic development are vexing problems. Strategies that promise progress on both fronts are especially appealing. The arguments we have offered above suggest that this is a very dangerous gamble for conservation planners to make, however.

The conservation community is made up of intelligent, dedicated individuals. They have honest disagreements and differences of opinion. Having said this, though, there is a natural human tendency to favor policies that both address issues of public concern and provide opportunities for one's own participation. Indirect approaches to conservation ICDPs create a demand for a cadre of consultants. They also open up a new source of funds: conservation programs have become development programs and have thereby gained access to the coffers of development agencies. Donors, however, must ask themselves if they would be spending their money more efficiently if they targeted it more carefully. Conservation advocates must ask themselves if they would achieve their ends more effectively if they defined their objectives more narrowly. 


\section{DIRECT PAYMENTS IN PRACTICE}

Contrary to the assertions one sometimes hears, direct payment programs have been in existence for quite some while, and have often proved very successful. Wealthy nations rely heavily on them. The best known conservation payment initiatives are the agricultural land diversion programs of high-income nations. In Europe, fourteen nations spent an estimated $\$ 11$ billion (1993-97) to divert well over 20 million hectares into long-term set-asides and forestry contracts (OECD 1997). In the United States, the Conservation Reserve Program (CRP) spends about \$1.5 billion annually to contract for 12 - 15 million hectares, an area twice the size of all national and state wildlife refuges in the lower 48 states (Clark and Downes 1999). In recent years, more direct environmental payment systems have been developed and are now being implemented (Claassen et al., 2001).

These conservation contracting programs account for only a few percent of agricultural support budgets, but they are among the fastest growing payments to farmers in high-income nations (OECD:14). Their dramatic growth is partly due to their popularity among various stakeholders (OECD:20) and the opportunities they afford for flexible targeting and adjustment to local conditions (OECD:48).

Nongovernmental organizations (NGOs) have also developed innovative direct payment approaches. The Delta Waterfowl Foundation, for example, has an "adopt-apothole" program that pays prairie farmers who protect nesting areas for ducks (Delta Waterfowl Foundation 2000). The Defenders of Wildlife have a program that rewards landowners for occupied wolf dens on their property (Brown 1999).

Direct payment initiatives are less common in low-income nations, but conservation pioneers are planning or experimenting with them in more than one dozen nations. Payments are being made to protect entire ecosystems and specific species, with diverse institutional arrangements existing among governments, firms, multilateral donors, communities, and individuals. A recent symposium ${ }^{\mathrm{vi}}$ highlighted the use of forest protection payments in Costa Rica, conservation leases for wildlife migration corridors in Kenya, conservation concessions on forest tracts in Guyana, and performance payments for endangered predators and their prey in Mongolia. South Africa and American Samoa have over a decade of experience with "contractual national parks," which are leased from communities. Other payment initiatives are being designed or are under way in Mexico, El Salvador, Colombia, Honduras, Guatemala, Panama, Russia, and Madagascar. ${ }^{\text {vii }}$

The mere existence of direct payment initiatives, however, does not imply that practitioners who use them have been successful in achieving conservation and development objectives. For example, Costa Rica's 5-year old PSA program (El Programa de Pago de Servicios Ambientales) is the longest-lived and best-known payment initiative for ecosystem services among low-income nations. No one knows, however, if the program has lead to the protection of forest that otherwise would have been cleared. All that practitioners have documented to date is that contracts have been signed and payments have been made. Even in high-income nations, where direct payment programs are more established, empirical analyses are rare. 
Thus, although we have put forth many arguments for the superiority of direct payment approaches to ecosystem and biodiversity protection, we acknowledge that no one has conducted a rigorous and systematic empirical evaluation to assess if an existing payment initiative is achieving the conservation and development objectives it purports to achieve. Carefully designed, empirical research on the use of conservation payments to achieve conservation and development goals in low-income nations is a critical next step.

\section{CONCLUSION}

Billions of dollars have been spent to stem the decline of native ecosystems in lowincome nations. A large proportion of these funds has been invested in indirect approaches that seek to support eco-friendly economic activities in and around endangered ecosystems. We argue that conservation donor and practitioners are likely to find direct payment approaches far more effective and efficient than these indirect approaches by virtue of the close link between the payments and the desired conservation outcomes.

After making our case for the superiority of direct payment approaches, we addressed the question, "If direct approaches are more desirable, why have indirect approaches been more commonly employed in recent years?" First, we acknowledged that instituting a direct payment approach amid the weak institutions of low-income nations is difficult. However, instituting any effective policy in such circumstances is difficult. Direct payments seem daunting precisely because the mechanism through which they achieve conservation and development objectives is explicit; cause and effect are easily identifiable. In contrast, the mechanisms through which indirect approaches will achieve conservation and development goals are typically vague. Indirect approaches thus facilitate wishful thinking among donors and practitioners who believe that large conservation payoffs can be achieved through small investments.

Moreover, a review of ICDP budgets suggests that indirect approaches to conservation investment steer much of the available funds into administration. ${ }^{\text {vii }}$ In contrast, a direct payment approach does not require the same throng of conservation and development consultants and thus may be less popular among the practitioners and consulting organizations that design conservation interventions.

While the obstacles to implementing a payment approach deserve careful consideration, we continue to believe that both conservation and development objectives could be more effectively achieved if more reliance were placed on direct payments. We acknowledge that direct payment approaches are not "silver bullets" that can be applied immediately and easily in all situations. Furthermore, broader policy interventions, such as removing perverse direct and indirect subsidies that encourage the loss of habitats and their biodiversity are also needed. If, however, the conservation community wants to get what it pays for, it must start tying its investments directly to its goals. Direct payment approaches to achieving conservation objectives offer the best hope for doing just that. 


\section{REFERENCES}

Alcorn, Janis, "Indigenous Resource Management Systems," in Grazia BorriniFeyerabend, (ed.), Beyond Fences: Seeking Social Sustainability in Conservation, IUCN, Gland (Switzerland), 1997.

Alston, Lee J., Gary D. Libecap, and Robert Schneider, "The Demand and Supply of Property Rights on the Frontier: The Cases of North America and Brazil," in Terry L. Anderson and Peter J. Hill (editors), The Privatization Process; A Worldwide Perspective (Lanham, MD: Rowman \& Littlefield), 203-236; at 205.

Anonymous, "Money the Best Way to Protect Biodiversity," News in Science, 3 December 2002, online at http://www.abc.net.au/science/news/stories/s739182.htm, accessed 12 March 2003.

Martine Antona, Estelle Motte, Jean-Michel Salles, Sigrid Aubert, and Rivo Ratsimbarison, "Property Rights Transfer in Madagascar Biodiversity Policies," paper presented to the BIOECON Working Group meeting on Property Rights Mechanisms for Biodiversity Conservation, Rome, 31 May, 2002.

Bond, I., The Economics of Wildlife and Landuse in Zimbabwe: An Examination of Current Knowledge and Issues (Harare: World Wildlife Fund), 1993.

Brandon, 1998.

Bruner, Aaron, Richard E. Rice, and Gustavo A. B. da Fonseca, "An Estimate of the Cost of Conservation," note appended with supplementary material to Stuart Pimm, et al., "Can We Defy Nature's End?" Science 293 (21 September 2001), 2207-2208, available online ...

Castro, G., and I. Locker, "Mapping Conservation Investments: An Assessment of Biodiversity Funding in Latin America and the Caribbean,” BSP, 2000.

CIFOR, UNESCO, UNESCO World Heritage Centre. 1999. World heritage forests: The world heritage convention as a mechanism for conserving tropical forest biodiversity. CIFOR Ad Hoc Publication. Bogor, Indonesia: CIFOR, UNESCO, UNESCO WHC.

James, Andrew, Kevin J. Gaston, and Andrew Balmford, "Can We Afford to Conserve Biodiversity?” BioScience 51, 1 (January 2001), 43-52

Global Environment Facility (GEF), Operational Report on GEF Projects, December 2000, available online at http://www.gefweb.org/Map/orgp_2000-12.pdf, accessed 30 July 2002, at p. 28. 
Honey, 1999

Peluso, Nancy L., "Coercing Conservation: The Politics of State Resource Control," in R.D. Lipschutz et K. Conca, eds., The State and Social Power in Global Environmental Politics (New York: Columbia University Press), 1992.

Poole, Peter, "Indigenous Peoples, Mapping and Biodiversity Conservation: An Analysis of Current Activities and Opportunities for Applying Geomatics Technologies," BSP 23, 1995.

Roe, D., Leader-Williams, N., and Dalal-Clayton, B., "Take Only Photographs, Leave Only Footprints: The Environmental Impacts of Wildlife Tourism," IIED Wildlife and Development Series, No. 10, London: International Institute for Environment and Development, 1997.

Salafsky, Nick, Bernd Cordes, John Parks, and Cheryl Hochman, "Evaluating Linkages Between Business, the Environment, and Local Communities: Final Analytical Results from the Biodiversity Conservation Network," BSP no. 59, 1999.

Sanderson, Steven with Shawn Bird, "The New Politics of Protected Areas," Chapter 15 , pp. 441-454.

de Soto, Hernando, The Mystery of Capital: Why Capitalism Succeeds in the West and Fails Everywhere Else (New York: Basic Books), 2001

Sullivan, Sian, "How Sustainable Is the Communalising Discourse of 'New' Conservation? The Masking of Difference, Inequality and Aspiration in The Fledgling 'Conservancies' of North-West Namibia," In D. Chatty, Displacement, forced settlement and conservation, (Oxford: Berghahn Press), in press.

Trivedi, Bijal P., “Conservation International Gets \$261 Million Windfall”, National Geographic Today, 12 December 2001, online at http://news.nationalgeographic.com/news/2001/12/1210_TVhotspots.html, accessed 12 March 2003.

M.Wells et al., Investing in Biodiversity: A Review of Indonesia's Integrated Conservation and Development Projects (East Asia Region, World Bank, Washington, DC, 1998).

The World Bank, Biodiversity in World Bank Projects: A Portfolio Review, World Bank Environment Department Paper no. 59, March 1998.

\footnotetext{
i One way to derive this number would be as follows. To derive this number, we use existing data and make some simple assumptions. Multilateral donors have contributed substantial funds. For example, the Global Environmental Facility had allocated some US\$1.311 billion through the year 2000 (GEF, 2000). The World Bank committed some $\$ 1.7$ billion in direct investment on biodiversity conservation
} 
projects between 1988 and 1997 (World Bank, 1998). Private actors have also made major contributions. The MacArthur Foundation provided in excess of \$200 million for biodiversity-related grants between 1987 and 1999. The Gordon and Betty Moore Foundation recently provided Conservation International with what has been described as "the largest grant ever awarded to a private environmental organization," \$261 million over 10 years (Trivedi, 2001). Categorizing expenditures by geography rather than institution, more than $\$ 3.25$ billion has been spent on biodiversity conservation in Latin America and the Caribbean (Castro and Locker, 2000). As about half of the World Bank's biodiversity-related expenditures have been allocated to Latin America and the Caribbean. This ratio might be common to most funders. If not, if, say, the ratio for European donors is different, or U. S. and Canadian funding was disproportionately focused on their hemispheric neighbors, we might suppose that European funding would be disproportionately focused on the Eastern Hemisphere to an offsetting degree. If we assume that the rate of funding for biodiversityrelated projects did not decline between 1998 and 2002, we might suppose that about $\$ 5$ billion has been allocated to the Western Hemisphere in total. If this represents half the world total, we would have our answer. The $\$ 10$ billion figure excludes investments made by host-country national governments.

ii In the words of one report, ICDPs have "become the predominant approach to most large-scale internationally financed conservation efforts in developing countries." (CIFOR, 1999). Others characterize ICDPs as "the now predominant" approach (Van Schaik and Rijksen, 2002), and report that billions of dollars have been invested in ICDPs (Terborgh and Boza, 2002). Popular terms for describing similar projects include "gestion de terroirs" and "community-based natural resource management." Our sense is that, while different titles are coined over time, similar types of field interventions are instituted under each.

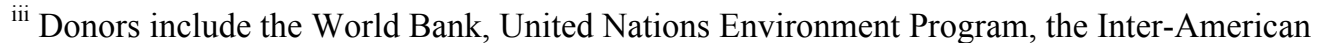
Development Bank, the Asian Development Bank, the European Union, the bilateral aid organizations of Canada, Germany, the Netherlands, Norway, Sweden, Switzerland, and the United States, and nongovernmental organizations such as the World Wildlife Fund, Conservation International, Cultural Survival, and the International Union for the Conservation of Nature (Wells et al. 1992; Brown and Wyckoff-Baird 1994; Conservation International 1994; Cultural Survival 1994; Simpson and Sedjo 1996; Southgate 1998; Honey 1999).

iv We should offer a couple of observations here. First, let us emphasize again that the authors of the study applied extremely generous criteria "To give our enterprises the 'benefit of the doubt,' we generally ranked them on their best year" (Salafsky, et al., 1999; p. 20). Second, we would not assert that conservation advocates could never identify profitable opportunities any more than we would make the equally ridiculous claim that the ventures private actors undertake are always profitable. Our point, rather, is that private parties are far more likely to be right than are conservation advocates with little investment expertise and often conflicting objectives.

$\mathrm{v}$ We assume that political considerations preclude the possibility of making a payment and taking physical possession.

vi "Direct Payments as an Alternative Conservation Investment," a symposium at the 16th Annual Meetings of the Society for Conservation Biology, Canterbury, England, 15 July 2002. For more detail, see http://epp.gsu.edu/pferraro/special/special.htm.

${ }^{\text {vii }}$ For more details and examples, see (Kiss, 2003) and http://epp.gsu.edu/pferraro/special/special.htm.

viii J. Peters, J. Agric. Environ. Ethics 11, 17 (1998). For example, Peters (1998), a former consultant to an African ICDP, estimated that 55\% of his ICDP's budget went to U.S.-based administrative overhead and expatriate technical consultants. Only $2 \%$ of the budget went to rural residents living around the endangered rain forest ecosystem. In contrast, existing direct payment initiatives have estimated administrative costs from $5 \%$ to $25 \%$ of the operating budget (Ferraro and Kiss, 2002). 